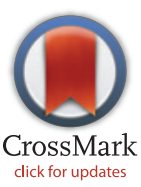

click for updates
RESEARCH ARTICLE

\section{Activin Receptor-Like Kinase Receptors ALK5 and ALK1 Are Both Required for TGFß-Induced Chondrogenic Differentiation of Human Bone Marrow-Derived Mesenchymal Stem Cells}

\author{
Laurie M. G. de Kroon ${ }^{1,2}$, Roberto Narcisi ${ }^{2}$, Esmeralda N. Blaney Davidson ${ }^{1}$, Mairéad \\ A. Cleary ${ }^{2,3}$, Henk M. van Beuningen ${ }^{1}$, Wendy J. L. M. Koevoet ${ }^{4}$, Gerjo J. V. M. van Osch ${ }^{2,4}$, \\ Peter M. van der Kraan ${ }^{1 *}$ \\ 1 Department of Rheumatology, Experimental Rheumatology, Radboud University Medical Center, \\ Nijmegen, the Netherlands, 2 Department of Orthopedics, Erasmus MC University Medical Center, \\ Rotterdam, the Netherlands, 3 Section of Veterinary Clinical Sciences, School of Veterinary Medicine, \\ University College Dublin, Dublin, Ireland, 4 Department of Otorhinolaryngology, Erasmus MC University \\ Medical Center, Rotterdam, the Netherlands \\ * Peter.vanderKraan@ radboudumc.nl
}

\section{OPEN ACCESS}

Citation: de Kroon LMG, Narcisi R, Blaney Davidson EN, Cleary MA, van Beuningen HM, Koevoet WJLM, et al. (2015) Activin Receptor-Like Kinase Receptors ALK5 and ALK1 Are Both Required for TGFß-Induced Chondrogenic Differentiation of Human Bone MarrowDerived Mesenchymal Stem Cells. PLoS ONE 10(12): e0146124. doi:10.1371/journal.pone.0146124

Editor: Kenneth B Marcu, Stony Brook University, UNITED STATES

Received: September 25, 2015

Accepted: December 14, 2015

Published: December 31, 2015

Copyright: $\odot 2015$ de Kroon et al. This is an open access article distributed under the terms of the Creative Commons Attribution License, which permits unrestricted use, distribution, and reproduction in any medium, provided the original author and source are credited.

Data Availability Statement: All relevant data are within the paper.

Funding: PMvdK received funding from the Dutch Arthritis Foundation (grant number 11-1-404; http:/l www.reumafonds.n//), and this work was funded by the Netherlands Institute for Regenerative Medicine (grant number FES0908; www.nirm.nl). Both funders had no role in study design, data collection and analysis, decision to publish, or preparation of the manuscript.

\section{Abstract}

\section{Introduction}

Bone marrow-derived mesenchymal stem cells (BMSCs) are promising for cartilage regeneration because BMSCs can differentiate into cartilage tissue-producing chondrocytes. Transforming Growth Factor $\beta$ (TGF $\beta$ ) is crucial for inducing chondrogenic differentiation of BMSCs and is known to signal via Activin receptor-Like Kinase (ALK) receptors ALK5 and ALK1. Since the specific role of these two TGF $\beta$ receptors in chondrogenesis is unknown, we investigated whether ALK5 and ALK1 are expressed in BMSCs and whether both receptors are required for chondrogenic differentiation of BMSCs.

\section{Materials \& Methods}

ALK5 and ALK1 gene expression in human BMSCs was determined with RT-qPCR. To induce chondrogenesis, human BMSCs were pellet-cultured in serum-free chondrogenic medium containing TGF $\beta 1$. Chondrogenesis was evaluated by aggrecan and collagen type Ila1 RT-qPCR analysis, and histological stainings of proteoglycans and collagen type II. To overexpress constitutively active (ca) receptors, BMSCs were transduced either with caALK5 or caALK1. Expression of ALK5 and ALK1 was downregulated by transducing BMSCs with shRNA against ALK5 or ALK1.

\section{Results}

ALK5 and ALK1 were expressed in in vitro-expanded as well as in pellet-cultured BMSCs from five donors, but mRNA levels of both TGF $\beta$ receptors did not clearly associate with chondrogenic induction. TGF $\beta$ increased ALK5 and decreased ALK1 gene expression in 
Competing Interests: The authors have declared that no competing interests exist. chondrogenically differentiating BMSC pellets. Neither caALK5 nor caALK1 overexpression induced cartilage matrix formation as efficient as that induced by TGF $\beta$. Moreover, short hairpin-mediated downregulation of either ALK5 or ALK1 resulted in a strong inhibition of TGF $\beta$-induced chondrogenesis.

\section{Conclusion}

ALK5 as well as ALK1 are required for TGF $\beta$-induced chondrogenic differentiation of BMSCs, and TGF $\beta$ not only directly induces chondrogenesis, but also modulates ALK5 and ALK1 receptor signaling in BMSCs. These results imply that optimizing cartilage formation by mesenchymal stem cells will depend on activation of both receptors.

\section{Introduction}

Articular cartilage is a connective tissue covering bone surfaces within synovial joints and its main functions are distributing forces and preventing friction between moving bones. Chondrocytes are the only cell population present in articular cartilage, and they are responsible for the production, maintenance and organization of cartilage matrix [1]. Once articular cartilage becomes damaged by an injury or joint disease, it is not regenerated. In the long run, articular cartilage defects get worse and patients suffer from joint pain and dysfunction [2]. Therefore, innovative treatments to regenerate cartilage tissue are highly necessary. However, to date, a procedure in which articular cartilage tissue is formed closely resembling native tissue's structure and properties still needs to be developed $[3,4]$.

To heal damaged cartilage, bone marrow-derived mesenchymal stem cells (BMSCs) are promising due to their capacity to differentiate into chondrocytes [5-11]. Unfortunately, thus far, results from BMSC-based therapies have been suboptimal due to variable levels of cartilage tissue formation and poor functional properties of the repair tissue formed [12-15]. To solve these issues regarding the functionality of BMSC-derived cartilage, we need to better understand the molecular mechanisms that control chondrogenic differentiation of BMSCs. Ultimately, this might lead to formation of cartilage tissue which yields similar properties as native cartilage and restores joint functionality.

Transforming growth factor $\beta$ (TGF $\beta$ ), originally described as Cartilage-Inducing Factor [16], is required for chondrogenic differentiation of human BMSCs $[5-9,11]$. TGF $\beta$ signals via type I and II serine/threonine kinase receptors [17]. Upon binding of TGF $\beta$ ligands to type II receptors, heteromeric complexes are formed with type I receptors [18-20]. Within a complex, type II receptors phosphorylate the kinase domain of type I activin receptor-like kinase receptors (ALKs) which then recruit and phosphorylate SMAD proteins. Phosphorylated SMAD proteins translocate to the nucleus, where they associate with transcriptional co-activators and co-repressors to modulate target gene expression in a cell type-specific manner [21-23].

Although in most cell types TGF $\beta$ signaling is conveyed through ALK5, multiple studies have identified ALK1 as an alternative type I receptor for TGF $\beta$ [24-30]. ALK5 is known to phosphorylate SMAD2 and SMAD3 proteins (SMAD2/3), and ALK1 phosphorylates SMAD1, SMAD5 and SMAD8 proteins (SMAD1/5/8) [22, 31]. Previously, our group demonstrated that both SMAD pathways are important in chondrogenic differentiation of BMSCs as blocking TGF $\beta$-induced phosphorylation of either SMAD2/3 or SMAD1/5/8 with chemical inhibitors prevented BMSC chondrogenesis [32]. However, the specific role of ALK5 and ALK1 receptors in chondrogenic induction of BMSCs with TGF $\beta$ remains unknown. As TGF $\beta$ is crucial for 
BMSC chondrogenesis and is known to activate ALK5 as well as ALK1 receptors, our aim was to elucidate whether ALK5 and ALK1 are required for TGF $\beta$-induced chondrogenic differentiation of human BMSCs.

\section{Materials and Methods}

Cell isolation and expansion

Human fetal bone marrow-derived mesenchymal stem cells. Primary human fetal BMSCs from one donor (donor F1) were purchased from ScienCell Research Laboratories (Carlsbad, CA, USA). Cells were culture-expanded in Mesenchymal Stem Cell Growth Medium (Lonza, Basel, Switzerland) supplemented with 1\% Penicillin-Streptomycin-Glutamine (Gibco/Thermo Fisher Scientific, Waltham, MA, USA) until subconfluency and stored in liquid nitrogen at passage 5. Per experiment, fetal BMSCs were defrosted and expanded for another 2 to 4 passages.

Human adult bone marrow-derived mesenchymal stem cells. After obtaining written informed consent from patients $(n=5)$, bone marrow aspirates were collected during total hip arthroplasty for osteoarthritis. This procedure was approved by the medical ethical committees of the Erasmus Medical Center, Rotterdam (\#METC 2004-142) and Albert Schweitzer Hospital, Dordrecht (\#METC 2011.07). Primary human adult BMSCs were isolated from the marrow aspirate from 5 donors (Donor A1 -A5) by plastic adherence. Adult BMSCs were seeded in $\alpha$-MEM (Gibco) containing 10\% pre-selected fetal calf serum (FCS; Lonza), $50 \mu \mathrm{g} / \mathrm{mL}$ gentamicine, $1.5 \mu \mathrm{g} / \mathrm{mL}$ fungizone (both from Gibco), $10^{-4} \mathrm{M} \mathrm{L}$-Ascorbic acid 2-phosphate (SigmaAldrich, St. Louis, MO, USA) and 1 ng/mL Fibroblast Growth Factor-2 (AbD Serotec, Kidlington, United Kingdom). Non-adherent cells were removed after 24 hours and adherent cells were further culture-expanded until subconfluency. Experiments were performed using adult BMSCs in passage 2 to 4 .

\section{Chondrogenic differentiation of human adult and fetal BMSCs}

BMSCs were centrifuged at $200 \mathrm{x}$ g for 8 minutes and the obtained cell pellets $\left(0.2 \times 10^{6} \mathrm{cells} / \mathrm{pel}-\right.$ let) were cultured for up to 21 days in $0.5 \mathrm{~mL}$ serum-free chondrogenic medium which consisted of DMEM-high glucose-GlutaMAX ${ }^{\mathrm{ww}}, 1.5 \mathrm{mg} / \mathrm{mL}$ fungizone, $50 \mathrm{mg} / \mathrm{mL}$ gentamicin, $1.0 \mathrm{mg} / \mathrm{mL}$ sodium pyruvate (all from Gibco), $6.25 \mu \mathrm{g} / \mathrm{mL}$ insulin, $6.25 \mu \mathrm{g} / \mathrm{mL}$ transferrin, $6.25 \mathrm{ng} / \mathrm{mL}$ selenious acid, $5.35 \mu \mathrm{g} / \mathrm{mL}$ linoleic acid, $1.25 \mathrm{mg} / \mathrm{mL}$ bovine serum albumin, $0.4 \mathrm{mg} / \mathrm{mL}$ L-proline, $10^{-4} \mathrm{M}$ L-Ascorbic acid 2-phosphate, $10^{-7} \mathrm{M}$ dexamethasone (all from Sigma-Aldrich) and $10 \mathrm{ng} / \mathrm{mL}$ TGF $\beta 1$ (adult BMSCs; R\&D Systems, Minneapolis, MN, USA and fetal BMSCs; Biolegend, San Diego, CA, USA). In parallel, pellets were cultured in chondrogenic medium without TGF $\beta 1$ supplementation in order to determine the effects of TGF $\beta$ on ALK5 and ALK1 expression. This was done with cells from donors A1 and F1 because only from these two donors a sufficient number of cells was available. Medium was renewed 2 or 3 times a week. Triplicate pellets were harvested for mRNA expression analysis and histological examination.

\section{Overexpression of caALK5 and caALK1}

Adenoviruses for constitutively active (ca) caALK5, caALK1 or LacZ were kindly provided by Dr. P. ten Dijke (Leiden University Medical Center, the Netherlands), and their preparation was described by Nakao et al. and Itoh et al. [22,33].

Viral overexpressions were performed in BMSCs from fetal donor F1 because a high number of cells was available. Moreover, BMSCs from this donor chondrogenically differentiated 
within 7 days which is preferred to reliably test the effect of viral transductions, as adenoviruses cannot integrate into the cell's genome. Furthermore, donor F1 tested negative for HIV which is an important requirement for lentiviral transductions. Due to ethical concerns, the HIV-status could not be tested in donors A1-A5.

Prior to cell pellet preparation, fetal BMSCs cultured in monolayer were transduced in serum-free DMEM-high glucose-GlutaMAX ${ }^{\mathrm{m}}$ (Gibco) with adenovirus overexpressing caALK5 or caALK1 or LacZ (control) at a multiplicity of infection (MOI) of $150 \mathrm{pfu} / \mathrm{cell}$ for 3 hours. Cells were washed and pellet-cultured in serum-free chondrogenic medium for 7 days. In the presence of TGF $\beta$, fetal BMSC pellets chondrogenically differentiated within 7 days as determined by ACAN and COL2A1 RT-qPCR analysis and histological examination of proteoglycans and collagen type II. To test whether constitutively active ALK5 or ALK1 receptor signaling induced chondrogenic differentiation, BMSCs either transduced with caALK5 or caALK1 were not stimulated with TGF $\beta$ and LacZ-transduced BMSCs were stimulated with TGF $\beta$.

To verify the overexpression of caALK5 and caALK1 in BMSC pellets one day after transduction, mRNA levels of ALK5 (= TGFBR1) and ALK1 (= ACVRL1) were determined by RTqPCR. In order to confirm that caALK5 induced SMAD2 phosphorylation (pSMAD2) and that caALK1 induced SMAD1/5/8 phosphorylation (pSMAD1/5/8), expression of pSMAD2 and $\mathrm{PSMAD} 1 / 5 / 8$ proteins were analyzed by Western blot in one day-cultured BMSC pellets transduced with caALK5, caALK1 or LacZ. Expression of pSMAD2 and pSMAD1/5/8 was compared between LacZ-transduced pellets (not exposed to TGF $\beta$ ) and pellets transduced either with caALK5 or caALK1.

\section{shRNA-mediated downregulation of ALK5 and ALK1 expression}

MISSION $®$ TRC-Hs1.5 shRNA clones (Sigma-Aldrich) targeting ALK5 (TRCN0000039773) or ALK1 (TRCN0000000355) and Empty Vector Control (SHC001) constructed in the pLKO.1-Puro plasmid vector were kindly provided as purified plasmid DNA by Dr. P. ten Dijke (Leiden University Medical Center, the Netherlands). Lentiviruses were packaged with one of the aforementioned pLKO.1-puro plasmid vectors as described below.

HEK293T cells (ATCC, Manassas, VA, USA) were co-transduced with $42.7 \mu \mathrm{g}$ pLKO.1-

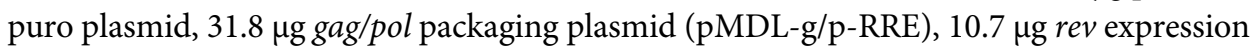
plasmid (RSV-REV) and $15.0 \mu \mathrm{g}$ VSV-G expression plasmid (pHIT-G) by calcium phosphate precipitation for 16 hours. Co-transductions were carried out in DMEM-high glucose-Gluta$\operatorname{MAX}^{\mathrm{sm}}$ (Gibco) containing 10\% FCS (Perbio Science, Erembodegem, Belgium), $0.01 \mathrm{mM}$ cholesterol (Sigma-Aldrich) and $1 \%$ pyruvate (Gibco). This medium (= supernatant) was renewed 16 hours after transduction, and 1\% Penicillin-Streptomycin-Glutamine (Gibco) was added. After 24 and 48 hours from the medium renewal, the supernatant was collected and filtered through a $0.45 \mu \mathrm{m}$ pore polyvinylidene fluoride Durapore filter (Millipore, Bedford, MA, USA). To concentrate lentiviral particles, $20 \%$ sucrose (Sigma-Aldrich) in PBS was pipetted under the supernatant and centrifuged at 134,350 $\mathrm{x}$ g for 2 hours (Sorvall WX80+, Thermo Fisher Scientific). After re-suspending the pellet in $210 \mu \mathrm{L}$ sterile PBS, the concentration of lentiviral particles was determined according to the INNOTEST ß HIV p24 Antigen monoclonal antibody assay (Fujirebio Europe, Gent, Belgium) and lentivirus titers were expressed as pg of $\mathrm{p} 24 / \mu \mathrm{L}$.

Fetal BMSCs, cultured in monolayer, were transduced for 24 hours with 1 pg p24 (lentivirus) per cell of either ALK5-shRNA, ALK1-shRNA or empty vector control in Mesenchymal Stem Cell Growth Medium (Lonza) supplemented with 1\% Penicillin-Streptomycin-Glutamine (Gibco) and $100 \mu \mathrm{g} / \mathrm{mL}$ protamine sulfate (Sigma-Aldrich). Following lentiviral transduction, 
cells were washed, trypsinized ( $0.25 \%$ trypsin; Gibco) and pellet-cultured in serum-free chondrogenic medium containing TGF $\beta 1$. After 7 days, chondrogenic induction was evaluated by determining expression of cartilage-specific genes (ACAN and COL2A1) and proteins (proteoglycan and collagen type II). In pellets cultured for 1 or 7 days, TGFBR 1 and ACVRL1 mRNA levels were analyzed by RT-qPCR to evaluate the efficiency of shRNA-mediated downregulation of ALK5 and ALK1.

\section{RNA extraction and real-time quantitative polymerase chain reaction}

Total cellular RNA was extracted from fetal BMSCs with TRI Reagent $\mathbb{R}$ (Sigma-Aldrich) according to manufacturer's protocol and contaminating DNA was removed by DNAse treatment (Invitrogen/Thermo Fisher Scientific). Adult BMSCs were homogenized in RNA-Bee (Tel-Test, Friendswood, TX, USA) and RNA was further purified using an RNeasy MicroKit (Qiagen, Hilden, Germany) with on-column DNA digestion. The concentration and purity of isolated RNA were measured on a NanoDrop $\AA$ spectrophotometer (Isogen Life Science, Utrecht, the Netherlands). 500ng of total RNA was converted into cDNA using Reverse Transcriptase (Invitrogen) according to manufacturer's instructions. Real-Time Quantitative Polymerase Chain Reaction (RT-qPCR) measurements were performed on a StepOnePlus ${ }^{\text {tw }}$ RealTime PCR System using SYBR Green Master mix (both from Applied Biosystems/Thermo Fisher Scientific). Primers are listed in Table 1.

\section{Gene expression analysis}

The Ct value of each primer was determined at a fixed threshold level of fluorescence and the amplification efficiency of all primers was between $90 \%$ and $110 \%$ (Table 1). Gene expression was normalized to expression of ribosomal protein 27 a (RPS27a), which was stably expressed between conditions and over time. Normalized gene expression levels in control conditions were set as $100 \%$. $-\Delta \mathrm{Ct}$ values were used for statistical analyses.

\section{Histology}

Pellets were fixed in $4 \%$ formalin in PBS for 24 hours followed by paraffin embedding. Sections ( $6 \mu \mathrm{m}$ thick) were mounted on Super Frost glass slides (Thermo Fisher Scientific). Proteoglycans were stained with $0.1 \%$ aqueous Safranin $O$ and sections were counterstained with $0.1 \%$ aqueous Fast Green (both from Brunschwig Chemie, Amsterdam, the Netherlands). To stain collagen type II using immunohistochemistry, sections were pre-treated with $0.1 \%$ pronase (Sigma-Aldrich) in PBS at $37^{\circ} \mathrm{C}$ for 30 minutes followed by 30 minutes-incubation with $1 \%$ hyaluronidase (Sigma-Aldrich) in PBS at $37^{\circ} \mathrm{C}$ for antigen retrieval. Sections were rinsed with PBS and non-specific binding sites were blocked with $10 \%$ normal goat serum (SouthernBiotech, Birmingham, AL, USA) in PBS containing 1\% BSA (PBS-1\%BSA). After 30 minutes, sections were incubated either with $0.4 \mu \mathrm{g} / \mathrm{mL}$ anti-collagen II primary antibody (mouse

Table 1. List of primers used for RT-qPCR.

\begin{tabular}{|c|c|c|c|c|}
\hline \multirow[b]{2}{*}{ Gene } & \multicolumn{2}{|c|}{ Primer sequences } & \multicolumn{2}{|c|}{ Details } \\
\hline & Forward primer & Reverse primer & Product & Slope \\
\hline RPS27a & TGGCTGTCCTGAAATATTATAAGGT & CCCCAGCACCACATTCATCA & $90 \mathrm{bp}$ & 3.4 \\
\hline TGFBR1 (ALK5) & CGACGGCGTTACAGTGTTTCT & СССАТСТGТСАСАСАAGTAАA & $65 b p$ & 3.3 \\
\hline ACVRL1 (ALK1) & CCATCGTGAATGGCATCGT & GGTCATTGGGCACCACATC & $63 b p$ & 3.2 \\
\hline$A C A N$ & GCCTGCGCTCCAATGACT & ATGGAACACGATGCCTTTCAC & $104 \mathrm{bp}$ & 3.3 \\
\hline COL2A1 & CACGTACACTGCCCTGAAGGA & CGATAACAGTCTTGCCCCACTT & $65 b p$ & 3.3 \\
\hline
\end{tabular}

doi:10.1371/journal.pone.0146124.t001 
monoclonal IgG1, raised against chicken collagen type II; II-II6B3 cell culture supernatant, Developmental Studies Hybridoma Bank, Iowa City, IA, USA) in PBS-1\%BSA or incubated with $0.4 \mu \mathrm{g} / \mathrm{mL}$ mouse-IgG1 as negative control (\#X0931, Dako, Glostrup, Denmark) in PBS$1 \% \mathrm{BSA}$ at room temperature for 60 minutes. Subsequently, sections were rinsed with PBS and anti-collagen type II antibody was detected using alkaline phosphatase-conjugated secondary antibody kit (1:50 in PBS-1\%BSA; \#HK-321-UK, Biogenex, San Ramon, CA, USA) according to manufacturer's protocol. Alkaline phosphatase activity, representing presence of collagen II protein, stained magenta after incubating sections with New Fuchsine substrate (Chroma, Köngen, Germany). Finally, sections were counterstained with hematoxylin (Sigma-Aldrich), air-dried and mounted with VectaMount ${ }^{\mathrm{mw}}$ (Vector Laboratories, Burlingame, CA, USA).

\section{Western blot analysis}

Phosphorylated SMAD2 (pSMAD2) and phosphorylated SMAD1/5/8 (pSMAD1/5/8) protein expression was analyzed by Western blot. Total proteins were isolated from fetal BMSC pellets using Cell Lysis Buffer (Cell Signaling Technology, Danvers, MA, USA) with 1\% protease inhibitor (Roche Diagnostics, Basel, Switzerland). Lysates were sonicated on ice using a Bioruptor $\mathbb{R}$ (Diagenode, Denville, NJ, USA). Sonified samples were centrifuged at $4^{\circ} \mathrm{C}$ at $16,000 \times \mathrm{g}$ for 15 minutes. In supernatant, the protein concentration was determined using the bicinchoninic acid assay (Thermo Fisher Scientific). $14 \mu \mathrm{g}$ of protein lysate was loaded on a $10 \%$ bisacrylamide gel for SDS-PAGE. Hereafter, proteins were transferred to a nitrocellulose membrane (GE Healthcare, Little Chalfont, United Kingdom) by wet transfer in Towbin buffer $\left(4^{\circ} \mathrm{C}\right)$ at $275 \mathrm{~mA}$ for 2 hours. Membranes were blocked with 5\% non-fat dry milk (pSMAD2) or with 5\% BSA (pSMAD1/5/8) in 0.1\% Tween in Tris-buffererd saline (TBST). Subsequently, membranes were incubated overnight at $4^{\circ} \mathrm{C}$ with either rabbit-anti-pSMAD2 $(1: 1000$; \#3101L, Cell Signaling Technology) or rabbit-anti-p-Smad1/5/8 (1:1000; \#9511L, Cell Signaling Technology) in $5 \%$ or $2 \%$ non-fat dry milk in TBST, respectively. After washing in TBST, membranes were incubated with anti-rabbit horseradish peroxidase (HPR)-linked secondary antibody (1:1500; \#P0448, Dako) in TBST containing 5\% non-fat dry milk (pSMAD2) or 2\% non-fat dry milk (pSMAD1/5/8) at room temperature for 1 hour. Proteins were visualized by detection of the HRP-signal using enhanced chemiluminescence (ECL) Prime Western Blotting Detection Reagent kit (GE Healthcare) following manufacturer's protocol.

To assess equal protein loading on pSMAD-stained membranes, GAPDH expression was analyzed. Membranes were blocked with Odyssey® Infrared Imaging System Blocking Buffer (LI-COR, Lincoln, NE, USA) for 1 hour, followed by incubation with mouse-anti-GAPDH antibody (1:10,000; \#G8795, Sigma-Aldrich) in Odyssey blocking buffer at room temperature for 1 hour. After washing with PBS containing 0.1\% Tween (PBST), membranes were incubated with donkey-anti-Mouse antibody conjugated with IRDye $\mathbb{B}$ 800CW (LI-COR) at room temperature for 30 minutes. GAPDH expression was detected using an Odyssey CLx Infrared Imaging System (LI-COR) and signal intensity was quantified with Image Studio ${ }^{\text {mt }}$ Lite (Version 3.1, LI-COR) following software instructions.

\section{Data analysis}

Quantitative data are represented as mean \pm standard deviation. Statistical analyses were performed using GraphPad Prism version 5.03 for Windows (GraphPad Software, San Diego, CA, USA). The normality and variance were evaluated by the Shapiro-Wilk test and Levene's Test of Homogeneity. Normally distributed data with equal variance were analyzed by an independent student's $t$ test or one-way ANOVA with Bonferroni post hoc test. Level of significance was set at $\mathrm{p}<0.05$. 


\section{Results}

\section{Levels of ALK5 and ALK1 expression in BMSCs are not associated with chondrogenic differentiation capacity}

Transforming Growth Factor- $\beta$ is known to signal either via ALK5 or ALK1 receptors, which intracellularly activate SMAD2/3 and SMAD1/5/8 signaling respectively. We first confirmed gene expression of ALK5 (TGFBR1) and ALK1 (ACVRL1) in in vitro-expanded BMSCs $(\mathrm{n}=5)$ and observed that their expression levels varied between donors (Fig 1).

We next investigated whether the mRNA levels of ALK5 and ALK1 at onset of chondrogenic differentiation (first 7 days of pellet culture) were related to the chondrogenic capacity of BMSCs at day 21. Moreover, gene expression of aggrecan (ACAN; Fig 2A) and collagen type II $\alpha 1$ (COL2A1; Fig 2B) was analyzed during onset of chondrogenesis. The overall chondrogenic capacity of each donor was determined by histological examination of proteoglycans and collagen type II deposition (Fig 2C) in pellets cultured for 21 days. Chondrogenic markers (Fig 2C) were highest expressed in pellets from donors A1, A2, A3 and F1 (defined as 'highly chondrogenic') and lowest in donors A4 and A5 (defined as 'poorly chondrogenic'). At onset of chondrogenesis, ALK5 gene (TGFBR1) expression pattern was similar in donors A1 and A5, with a high expression at the start of culture and an increase over time (Fig 2D). The other 4 donors displayed lower TGFBR1 expression than donors $\mathrm{A} 1$ and $\mathrm{A} 5$ and stable or decreasing expression over the 7 days of culture (Fig 2D). ALK1 mRNA (ACVRL1) levels remained rather stable over time in donors $\mathrm{A} 1, \mathrm{~A} 3, \mathrm{~A} 5$ and $\mathrm{F} 1$, while in donors $\mathrm{A} 2$ and $\mathrm{A} 4$ we generally observed a lower expression compared to the other donors (Fig 2E). Combined, these data indicate that ALK5 and ALK1 are expressed in human BMSCs, but with no clear association between mRNA levels of both TGF $\beta$ receptors and the chondrogenic capacity of BMSCs.

\section{TGF $\beta$ increases ALK5 and decreases ALK1 gene expression in BMSCs}

As an increase in TGF $\beta$ levels and in the number of receptors might result in enhanced sensitivity of cells to TGF $\beta$ [34], we investigated whether TGF $\beta$ modulated TGFBR1 (ALK5) and
A

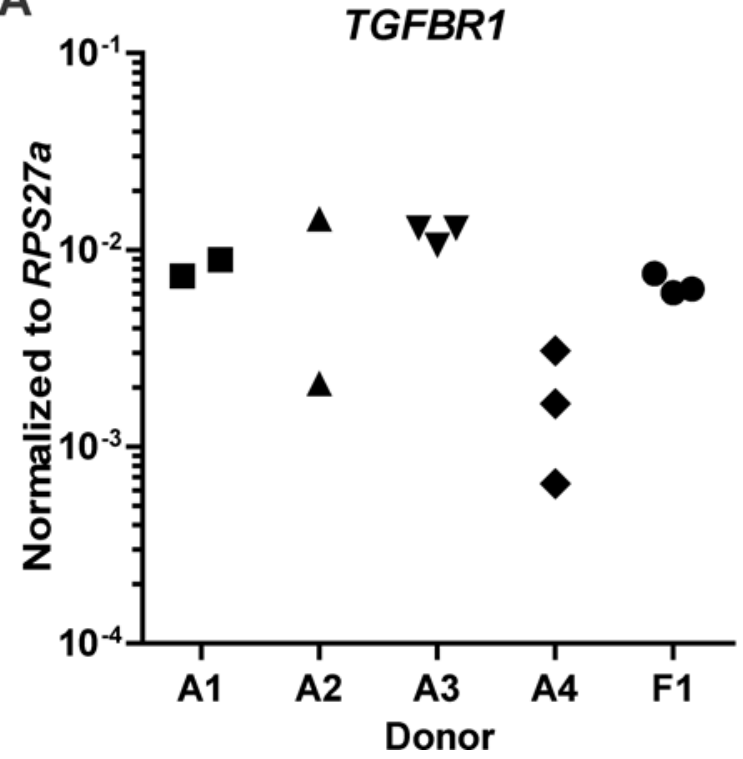

B

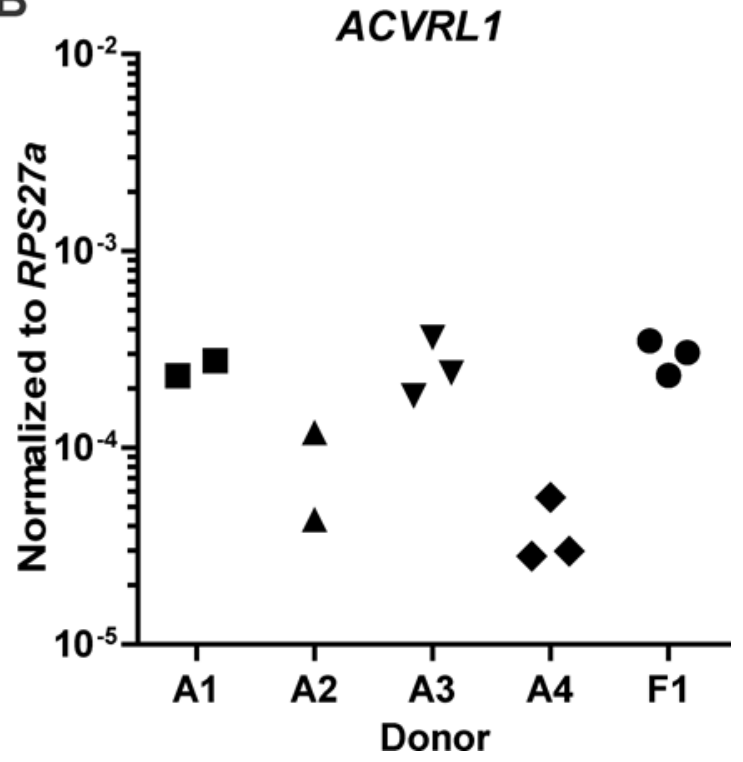

Fig 1. ALK5 and ALK1 are expressed in human bone marrow-derived mesenchymal stem cells (BMSCs). In human BMSCs, obtained from four adult donors (A1 -A4) and one fetal donor (F1), gene expression levels of ALK5 (= TGFBR1) (A) and ALK1 (= ACVRL1) (B) were analyzed using RT-qPCR. Gene expression was normalized to reference gene RPS27a. Each data point represents one measurement.

doi:10.1371/journal.pone.0146124.g001 

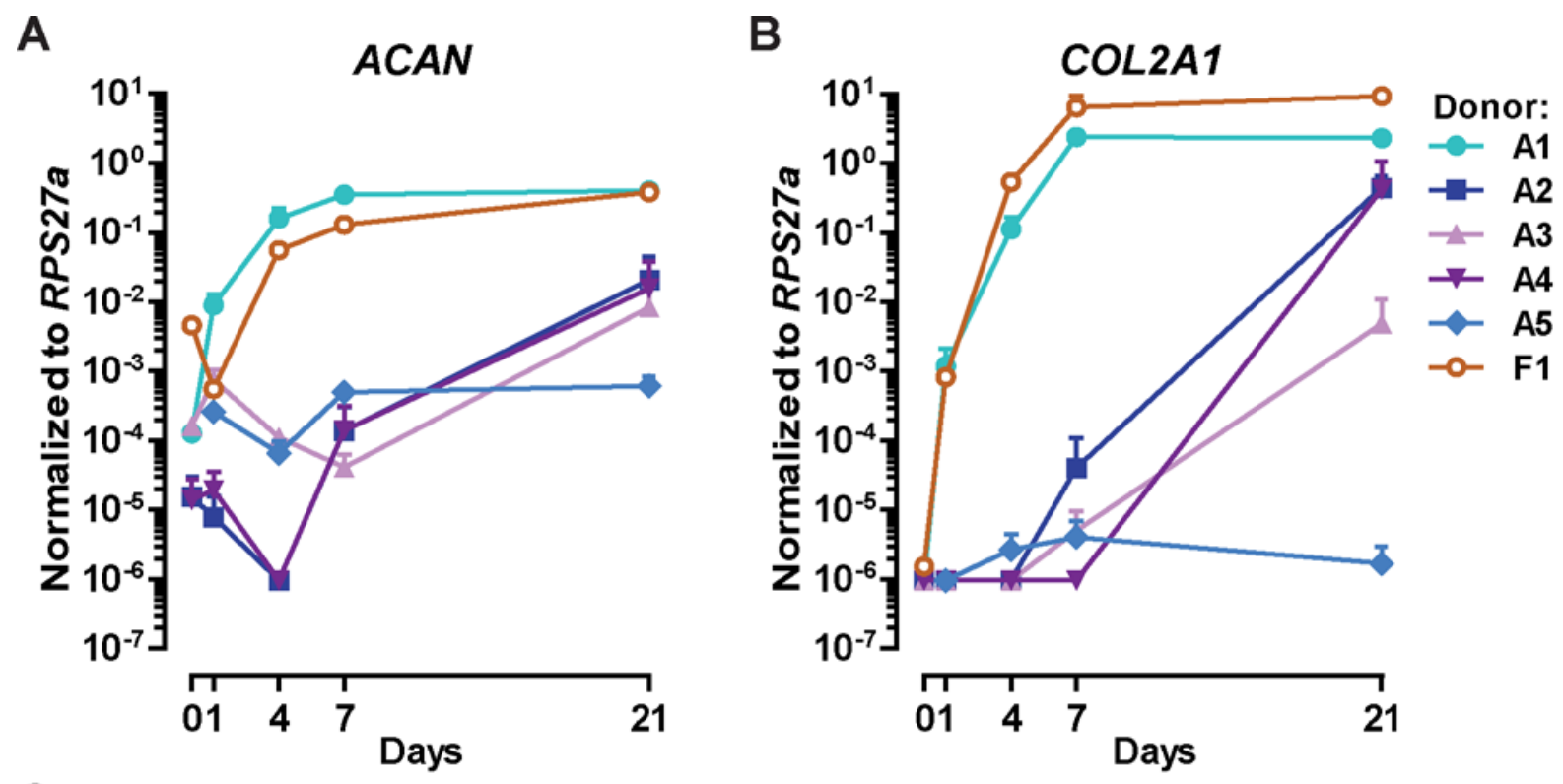

C

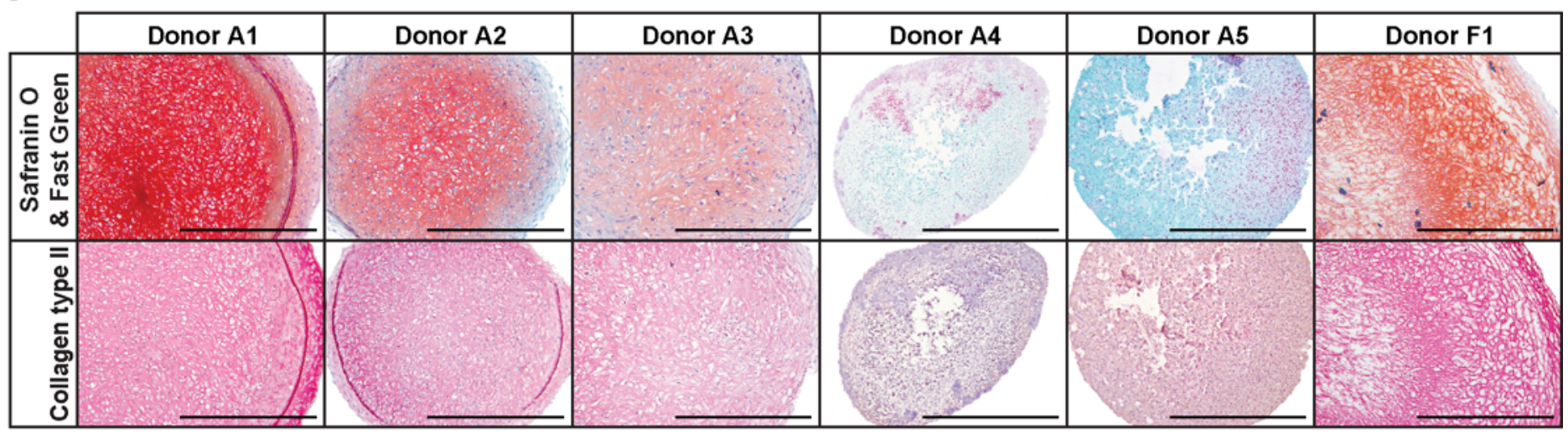

D

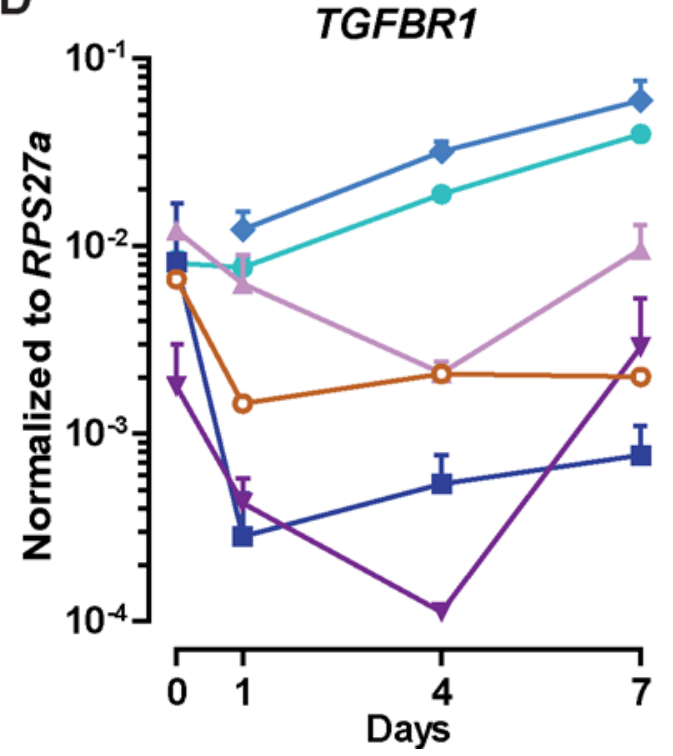

E

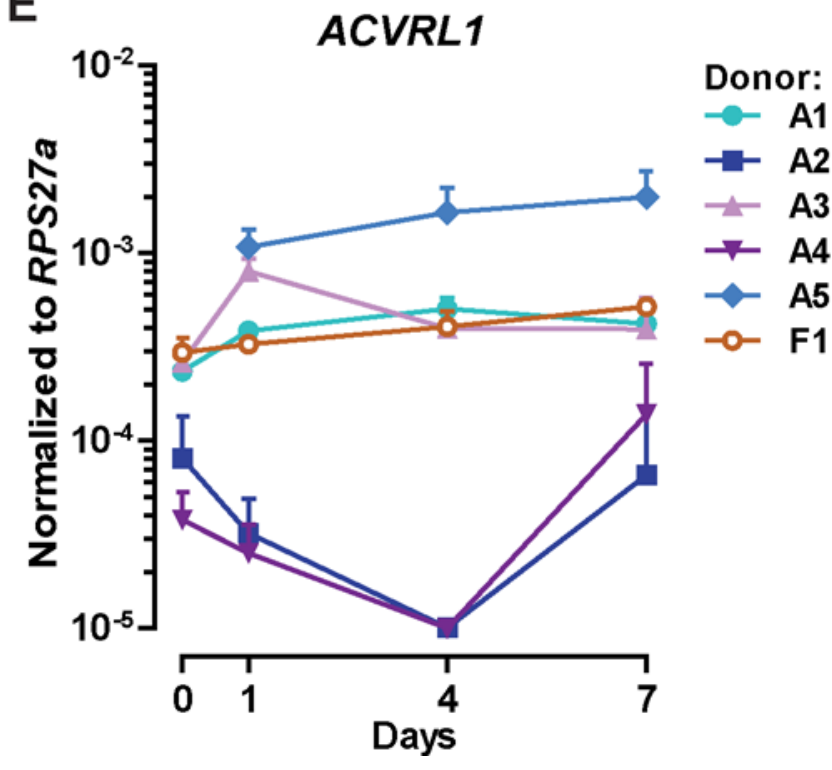


Fig 2. Gene expression levels of ALK5 (TGFBR1) and ALK1 (ACVRL1) are not associated with the chondrogenic capacity of human BMSCs. To induce chondrogenesis, BMSCs (passage 2-4) from adult donors A1 -A5 and fetal donor F1 were pellet-cultured in chondrogenic medium and stimulated with TGF $\beta$. Cartilage-specific gene expression of aggrecan $(A C A N)$ (A) and collagen type lla1 (COL2A1) (B) was determined in BMSCs cultured for $0,1,4,7$ and 21 days using RT-qPCR. Cartilage-specific protein depositions of proteoglycans (C; upper panel) and collagen type II (C; lower panel) were stained in sections of 21 days-cultured pellets. To stain proteoglycans, sections were stained with Safranin O (red/orange) and Fast Green (blue) was used as counterstaining. Collagen type II was stained immunohistochemically (pink) and hematoxylin (purple) was used as counterstaining. Representative images of consecutive pellet sections per donor are shown and the scale bar represents $500 \mu \mathrm{m}$. TGFBR1 (D) and ACVRL1 (E) expression levels were measured in BMSC monolayer (day 0) and pellets cultured for 1, 4 and 7 days. Gene expression was normalized to reference gene RPS27a. Data points represent mean \pm SD of triplicate BMSC pellets per donor per time point.

doi:10.1371/journal.pone.0146124.g002

ACVRL1 (ALK1) expression in BMSC pellets in donors A1 and F1 cultured for 1, 4 or 7 days. Compared to unstimulated pellets, TGF $\beta$ significantly induced TGFBR1 expression in pellets from donor A1 and donor F1 at day 1, 4, and 7 (Table 2). More specifically, TGF $\beta$ enhanced transcript levels of TGFBR 1 in donor F1 about 2 -fold at all time points measured, whereas in donor A1 TGF $\beta$ continuously increased TGFBR1 mRNA levels over time; 2.55 -fold at day 1 , 3.31-fold at day 4 and 7.58-fold at day 7. Contrary to TGFBR1 expression, ACVRL1 appeared to be significantly downregulated by TGF $\beta$ in both donors tested (Table 2). The inhibiting effect of TGF $\beta$ on ACVRL1 expression was more pronounced on day 4 than on day 1 in donor A1 (from -1.93-fold at day 1 to -3.30-fold at day 4) as well as in donor F1 (from -2.38-fold at day 1 to -3.32 -fold at day 4). At day 7, ACVRL1 mRNA levels were stronger decreased by TGF $\beta$ in donor A1 (-3.98-fold) than in donor F1 (-2.72-fold). Altogether, our data show that TGF $\beta$ regulates gene expression of its ALK5 and ALK1 receptors in chondrogenically differentiating BMSCs by enhancing TGFBR1 and decreasing ACVRL1 expression.

The effect of TGF $\beta$ on TGFBR1 and ACVRL1 was evaluated in BMSC pellets from donor A1 and donor F1 cultured in chondrogenic medium with TGF $\beta$ or without (= unstimulated) for 1 , 4 or 7 days. Gene expression was normalized to reference gene RPS27a. Data are expressed as fold change relative to unstimulated pellets and the mean \pm SD of triplicate BMSC pellets per donor per time point are shown.

\section{Overexpression of caALK5 or caALK1 receptors does not induce chondrogenic differentiation as efficiently as TGF $\beta$}

Since it was unknown whether TGF $\beta$ induces chondrogenesis through activation of its ALK5 or ALK1 receptor, we tested whether overexpression of either constitutively active (ca) caALK5 or caALK1 receptors induced chondrogenic differentiation of BMSCs.

In one day-cultured pellets we confirmed overexpression of TGFBR1 following caALK5 transduction (Fig 3A) and ACVRL1 overexpression following caALK1 transduction (Fig 3B). Whereas overexpression of caALK1 did not change TGFBR1 expression (Fig 3A), caALK5 overexpression reduced mRNA levels of ACVRL1 (Fig 3B). We also verified that caALK5 and caALK1 receptors phosphorylated their downstream signaling proteins SMAD2/3 (Fig 3C) and SMAD1/5/8 (Fig 3D) without prior activation by TGF $\beta$ and dimerization with type II receptors.

Table 2. TGF $\beta$ increases TGFBR1 (ALK5) and decreases ACVRL1 (ALK1) in human BMSC pellets.

\begin{tabular}{|c|c|c|c|c|c|c|c|c|}
\hline \multirow[b]{2}{*}{ Day } & \multicolumn{4}{|c|}{ TGFBR1 fold change (Mean \pm SD) } & \multicolumn{4}{|c|}{ ACVRL1 fold change (Mean \pm SD) } \\
\hline & Donor A1 & P-value & Donor F1 & P-value & Donor A1 & P-value & Donor F1 & P-value \\
\hline 1 & $2.55 \pm 0.39$ & 0.010 & $1.98 \pm 0.22$ & 0.001 & $-1.93 \pm 0.21$ & 0.040 & $-2.38 \pm 0.30$ & 0.001 \\
\hline 4 & $3.31 \pm 0.27$ & 0.001 & $2.24 \pm 0.12$ & $<0.001$ & $-3.30 \pm 0.51$ & 0.003 & $-3.32 \pm 0.74$ & 0.001 \\
\hline 7 & $7.58 \pm 0.26$ & $<0.001$ & $2.34 \pm 0.19$ & 0.005 & $-3.98 \pm 1.06$ & 0.001 & $-2.72 \pm 0.20$ & $<0.001$ \\
\hline
\end{tabular}

doi:10.1371/journal.pone.0146124.t002 
A

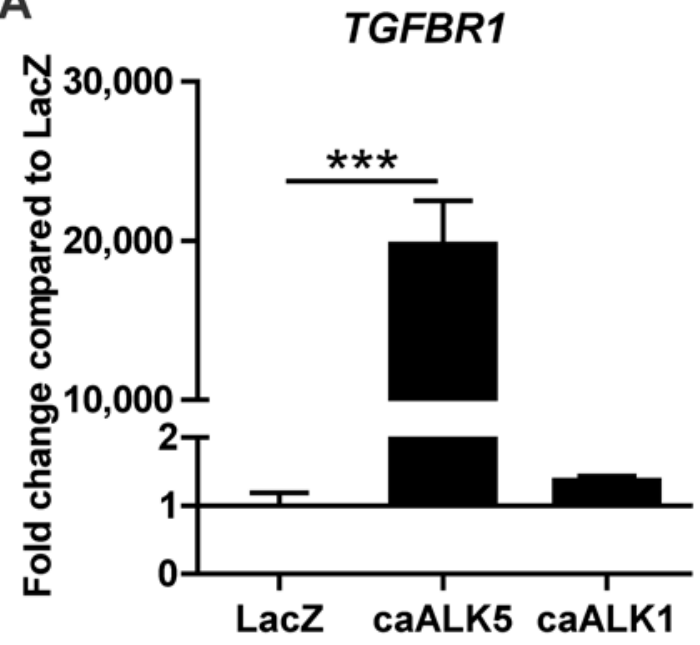

C

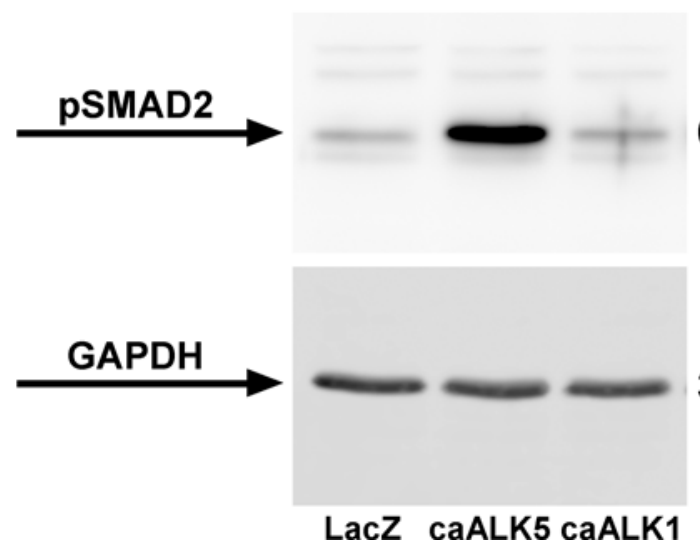

B

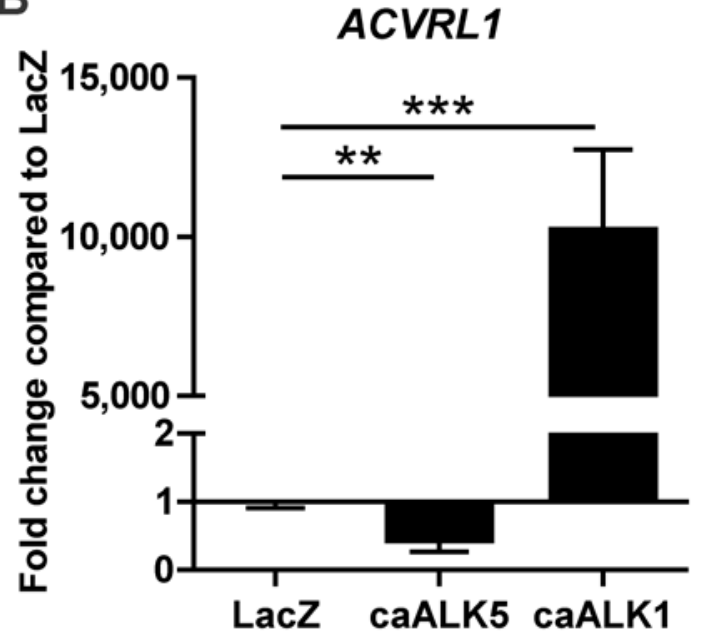

D

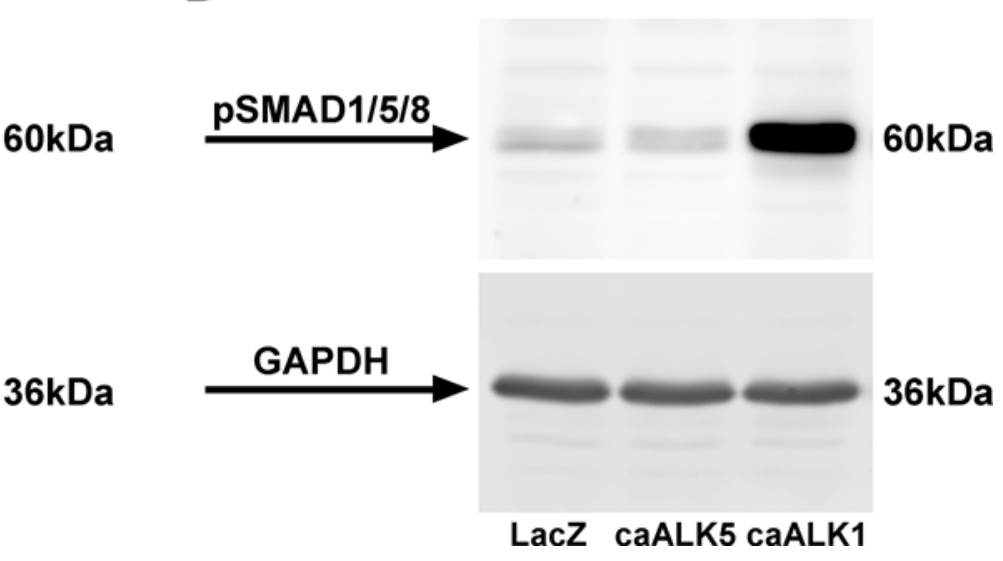

Fig 3. BMSCs overexpressing either constitutively active (ca) caALK5 or caALK1 express enhanced levels of phosphorylated SMAD2/3 and SMAD1/5/8 proteins, respectively. Human fetal BMSCs (donor F1) were transduced with adenoviral caALK5, caALK1 or LacZ as control and pelletcultured in chondrogenic medium for 1 day. Transduction efficiency of caALK5 and caALK1 was evaluated after gene expression analysis of TGFBR1 (A) and ACVRL1 (B). Gene expression was normalized to reference gene RPS27a and data are expressed as fold change relative to normalized gene levels in LacZ-transduced BMSCs. Bars represent mean \pm SD from triplicate pellets of 1 representative experiment (out of 3 ), ${ }^{* *} p<0.01 ; * * * p<0.001$. Constitutively active receptor signaling of ALK5 and ALK1 was evaluated by Western blot analyses of phosphorylated SMAD (pSMAD) proteins; pSMAD2/3 (C) and pSMAD1/5/8 (D) using GAPDH as loading control.

doi:10.1371/journal.pone.0146124.g003

Next, we determined whether overexpression of either caALK5 or caALK1 induced chondrogenic differentiation of human fetal BMSCs similar to chondrogenesis induced by TGF $\beta$. Chondrogenic differentiation was evaluated by comparing expression of cartilage matrix-specific genes (ACAN and COL2A1) and proteins (proteoglycans and collagen type II) between caALK5- or caALK1-transduced pellets cultured in the absence of TGF $\beta$ and the control condition (LacZ-transduced pellets stimulated with TGF $\beta$ ). Compared to the LacZ control stimulated with TGF $\beta$, caALK5-transduced pellets expressed ACAN 99.6\% lower (Fig 4A) and COL2A1 99.9\% lower (Fig 4B). In caALK1-transduced pellets $A C A N$ was $92.7 \%$ (Fig 4A) and COL2A1 was $99.6 \%$ (Fig 4B) lower expressed than in LacZ-transduced pellets exposed to TGF $\beta$. Consistent with these findings, caALK5-transduced pellets did not stain positive for proteoglycans (Fig 4C; upper panel) or collagen type II (Fig 4C; lower panel), and caALK1transduced pellets stained weakly positive for the two cartilage-specific proteins. In contrast, 
A

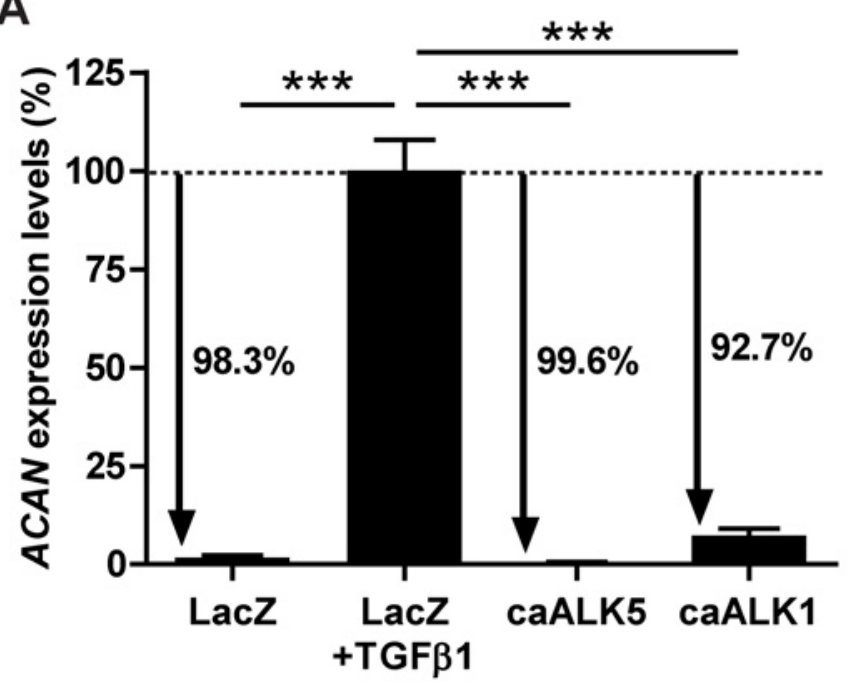

B

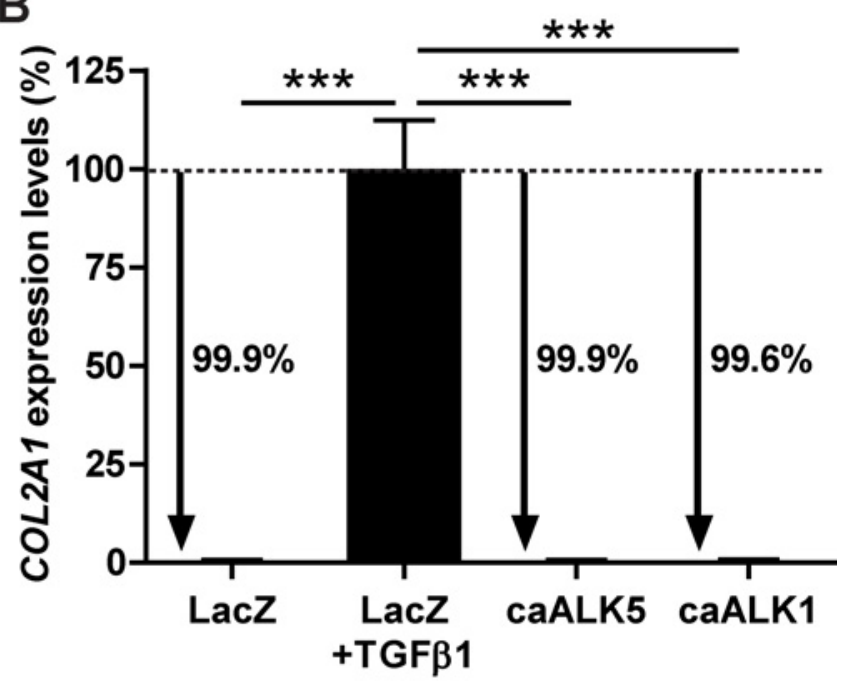

C

\begin{tabular}{|c|c|c|c|c|}
\hline & LacZ & LacZ + TGF $\beta 1$ & caALK5 & caALK1 \\
\hline 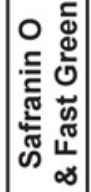 & & & & \\
\hline 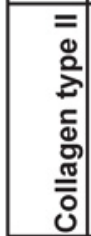 & 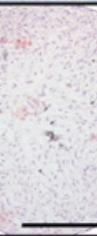 & & 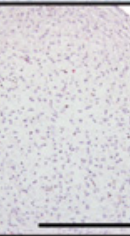 & \\
\hline
\end{tabular}

Fig 4. Constitutively active (ca) caALK5 and caALK1 receptors do not induce BMSC chondrogenesis as efficiently as TGF $\beta$ does. Human fetal BMSCs (donor F1) transduced with adenoviral caALK5, caALK1 or LacZ as control were pellet-cultured in chondrogenic medium for 7 days. Only LacZtransduced pellets were exposed to TGF $\beta$ to compare if either caALK5 or caALK1 induced chondrogenesis as efficiently as induced by TGF $\beta$.

Chondrogenesis was evaluated by cartilage-specific gene expression analysis of $A C A N(\mathbf{A})$ and COL2A1 (B) and by staining proteoglycans with Safranin O/ Fast Green (C; upper panel) and collagen type II with immunohistochemistry (C; lower panel). Representative images of consecutive pellet sections per condition are shown and the scale bar represents $500 \mu \mathrm{m}$. Gene expression was normalized to reference gene RPS27a and data are expressed as \% relative to normalized gene levels in LacZ-transduced pellets stimulated with TGF $\beta$. Bars represent mean \pm SD from quadruplet pellets of 1 representative experiment (out of 3 ), ${ }^{* * *} p<0.001$.

doi:10.1371/journal.pone.0146124.g004

LacZ-transduced pellets displayed intense staining of proteoglycans and collagen type II after 7 days stimulation with TGF $\beta$ (Fig 4C), confirming that only in this condition BMSCs differentiated and deposited a high amount of cartilage matrix. Taken together, these data indicate that neither constitutively active ALK5 nor constitutively active ALK1 induce chondrogenic differentiation of BMSCs as efficient as TGF $\beta$.

\section{Downregulation of either ALK5 or ALK1 expression in BMSCs inhibits TGF $\beta$-induced chondrogenic differentiation}

To further determine the role of ALK5 and ALK1 receptors in chondrogenesis initiated by TGF $\beta$, we investigated whether downregulation of either ALK5 or ALK1 expression abrogated TGF $\beta$-induced chondrogenic differentiation of BMSCs. ALK5 and ALK1 were downregulated 
by transducing human fetal BMSCs, cultured in monolayer, with a lentivirus overexpressing either ALK5 short hairpin RNA (ALK5-shRNA) or ALK1-shRNA. Following transduction, BMSCs were pellet-cultured in chondrogenic medium.

At day 1 and 7 of chondrogenic induction we verified the efficiency of shRNA-mediated downregulation by gene expression analysis of TGFBR1 and ACVRL1. Compared to the control condition at both time points, TGFBR1 expression was about $50 \%$ downregulated by ALK5-shRNA (Fig 5A) and ACVRL1 expression was about 50\% downregulated by ALK1-shRNA (Fig 5B). In addition, TGFBR1 mRNA levels were not affected by ALK1-shRNA (Fig 5A), but ACVRL1 was higher expressed in the ALK5-shRNA condition than in the control condition at day 7 (Fig 5B).The effect of shRNA-mediated ALK5 and ALK1 downregulation on TGF $\beta$-induced chondrogenic differentiation of BMSCs was determined by ACAN and COL2A1 gene expression analysis and examining deposition of proteoglycans and collagen type II in pellets stimulated with TGF $\beta$ for 7 days. Compared to control vector-transduced pellets stimulated with TGF $\beta$, ALK5-shRNA reduced expression levels of ACAN by $98.8 \%$ (Fig 5C) and COL2A1 by $99.9 \%$ (Fig 5D), resulting in the same low ACAN and COL2A1 mRNA levels as in the unstimulated control condition. ALK1-shRNA reduced ACAN expression by $62.6 \%$ (Fig 5C) and COL2A1 expression by $87.2 \%$ (Fig 5D) compared with the TGF $\beta$-stimulated control condition. Furthermore, we observed that control vector-transduced pellets exposed to TGF $\beta$ stained strongly positive for proteoglycans (Fig 5E; upper panel) and collagen type II (Fig 5E; lower panel), whereas TGFß-stimulated pellets overexpressing ALK1-shRNA were only weakly positive for both cartilage matrix molecules. Moreover, pellets consisting of ALK5-shRNA-transduced BMSCs did not stain positive for proteoglycans nor for collagen type II, despite stimulation with TGF $\beta$ (Fig 5E). Thus, shRNA-mediated downregulation of ALK5 or ALK1 results in an abrogation of TGF $\beta$-induced chondrogenic differentiation of BMSCs.

\section{Discussion}

In this study we investigated the involvement of ALK5 and ALK1 receptors in TGF 3 -induced chondrogenic differentiation of BMSCs. We show that TGF $\beta$ modulated gene expression of its receptors in BMSCs by increasing ALK5 whilst decreasing ALK1, although mRNA levels of ALK5 and ALK1 did not associate with the chondrogenic differentiation capacity. Overexpression of either caALK5 or caALK1 receptors did not induce chondrogenesis as efficiently as that induced by TGF $\beta$, and downregulating either ALK5 or ALK1 blocked cartilage formation in TGF $\beta$-stimulated BMSCs. Taken together, these findings indicate that both ALK5 and ALK1 are required for TGF $\beta$-induced chondrogenic differentiation of human BMSCs.

Although TGF $\beta$ is well-known to induce chondrogenic differentiation, no study has determined whether TGF $\beta$ induces chondrogenesis through activation of its ALK5 or ALK1 receptor. Therefore, in the present study we overexpressed either constitutively active ALK5 or constitutively active ALK1 and downregulated mRNA expression of the two TGF $\beta$ receptors in BMSCs. The characteristic of constitutively active ALK receptors is that they phosphorylate downstream SMAD proteins without prior activation by TGF $\beta$, which allowed us to determine whether TGF $\beta$ induces chondrogenic differentiation through activation of its ALK5 or ALK1 receptor. Despite ALK5 is considered to be the 'classical' TGF $\beta$ receptor, overexpression of caALK5 did not induce chondrogenesis. Previously, caALK1 overexpression was reported to fail to promote cartilage nodule formation in ATDC5 cells (chondrogenic mouse teratocarcinoma cell line) [35]. Here, we demonstrate that caALK1 overexpression slightly induced cartilage matrix formation in BMSCs, albeit not comparable to TGF $\beta$-induced matrix formation. Together these results suggest that, to induce chondrogenesis, activation of either ALK5 or 
A

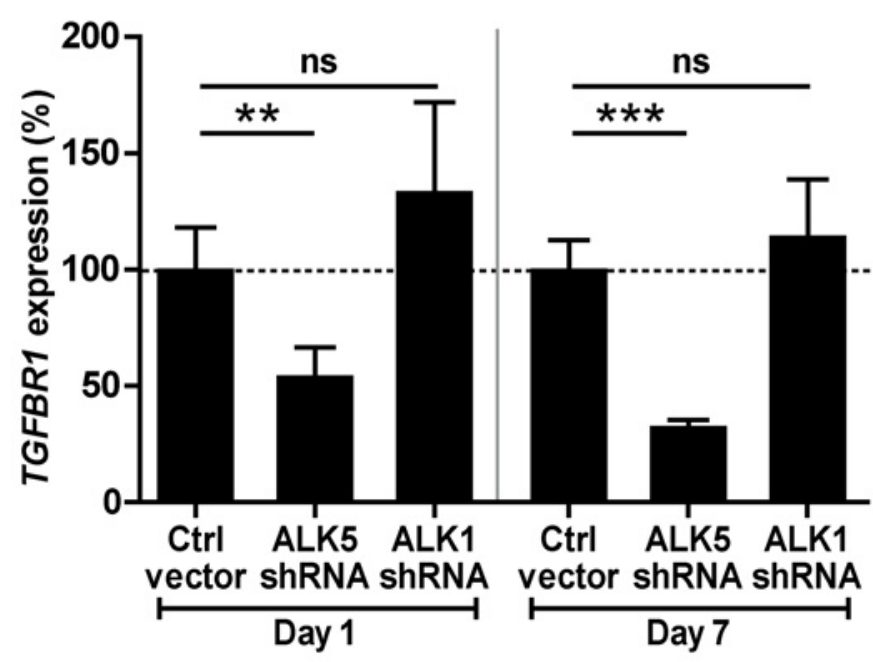

C

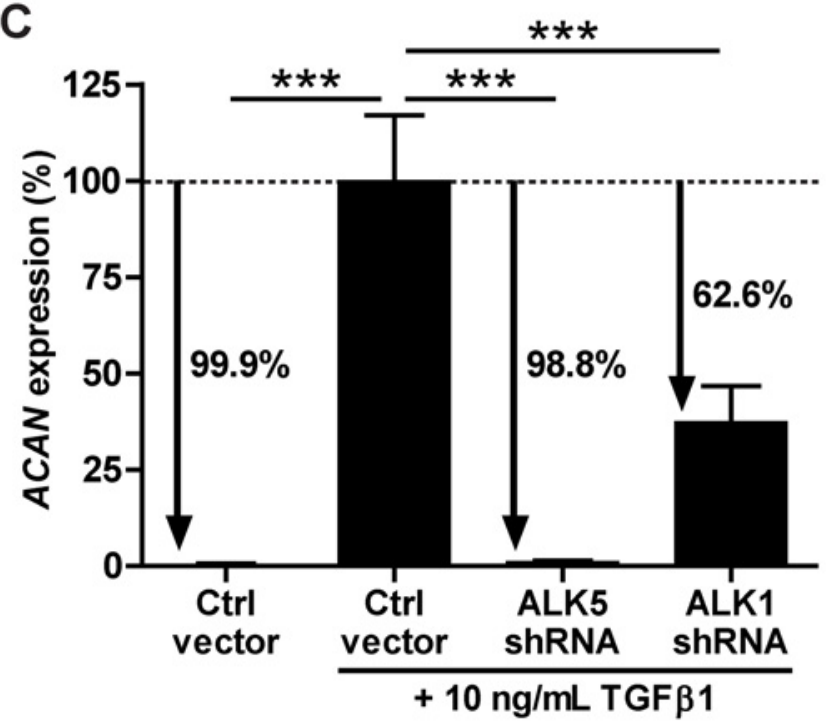

B

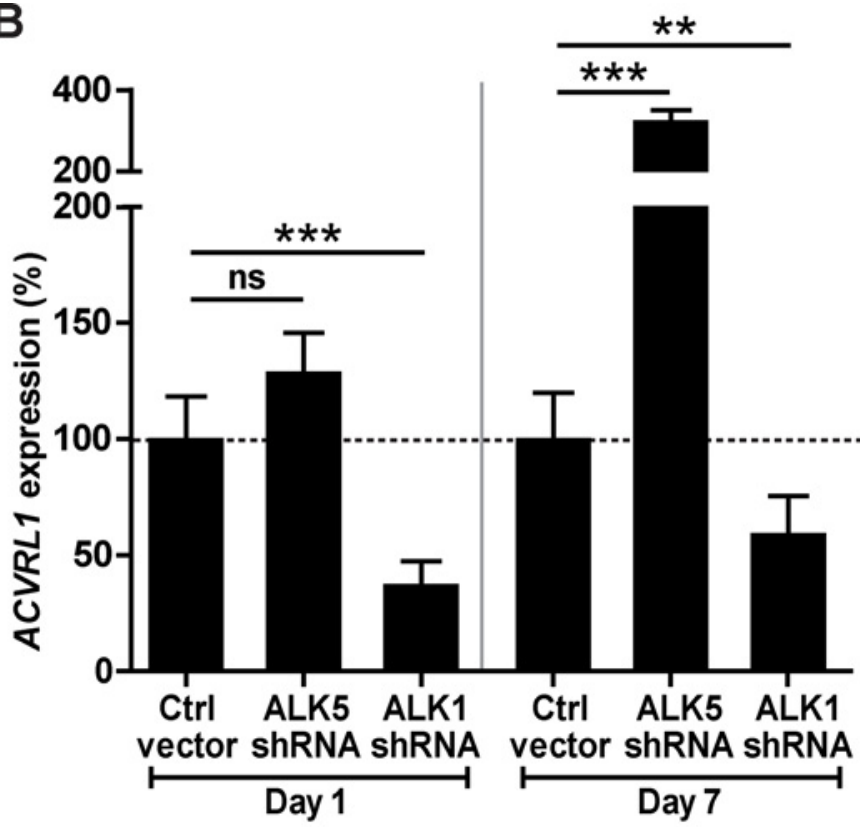

D

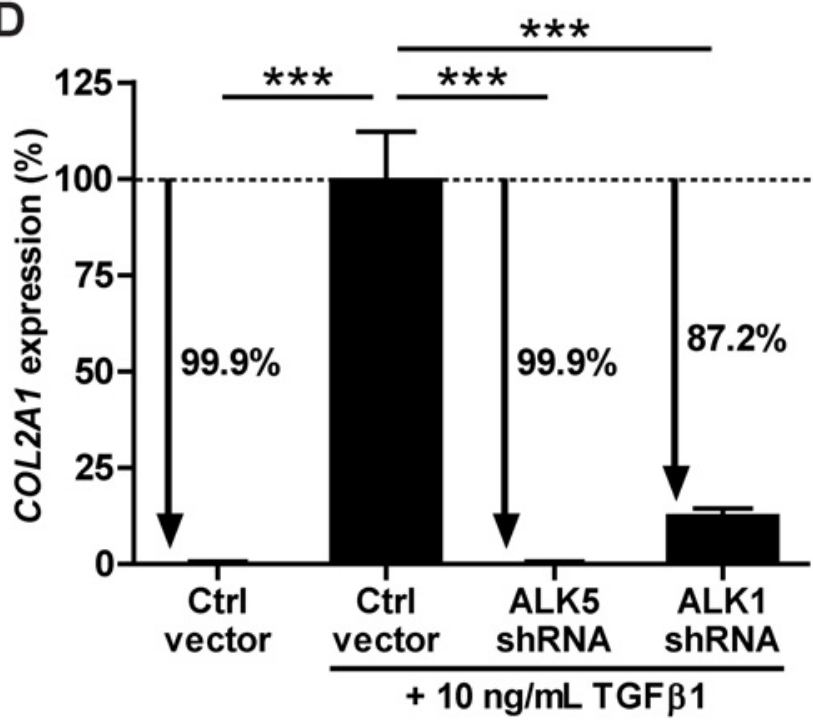

E

\begin{tabular}{|c|c|c|c|c|}
\hline & Ctrl vector & Ctrl vector+TGF $\beta 1$ & ALK5-shRNA+TGF $\beta 1$ & ALK1-shRNA+TGF $\beta 1$ \\
\hline 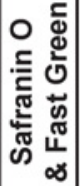 & & & & 2 \\
\hline 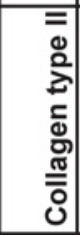 & & & & \\
\hline
\end{tabular}


Fig 5. shRNA-mediated downregulation of either ALK5 or ALK1 inhibits TGF $\beta$-induced chondrogenic differentiation of BMSCs. Human fetal BMSCs (donor F1) were transduced with lentiviral ALK5-shRNA, ALK1-shRNA or empty vector as control (Ctrl vector) and pellet-cultured in chondrogenic medium containing TGF $\beta$. Short hairpin RNA-mediated downregulation of ALK5 and ALK1 was determined by gene expression of TGFBR1 (A) and ACVRL1 (B) in pellets cultured for 1 or 7 days. The effect of ALK5-shRNA and ALK1-shRNA on TGFB-induced chondrogenesis was evaluated by transcript analysis of $A C A N(C)$ and COL2A1 (D) and by staining proteoglycans with Safranin O/Fast Green (E; upper panel) and collagen type II with immunohistochemistry (E; lower panel) in pellets cultured for 7 days. Representative images of consecutive pellet sections per condition are shown and the scale bar represents $500 \mu \mathrm{m}$. Gene expression was normalized to reference gene RPS27a and data are expressed as \% relative to normalized mRNA levels in control vectortransduced pellets stimulated with TGF $\beta$. Bars represent mean \pm SD of quadruplet pellets from 1 representative experiment (out of 3 ), ns $=$ not significant; ${ }^{*} \mathrm{p}<0.01 ;{ }^{* *} \mathrm{p}<0.001$.

doi:10.1371/journal.pone.0146124.g005

ALK1 is insufficient. Since the abundance and timespan of SMAD phosphorylation has been demonstrated to influence the cell's responses [36,37], one has to take into account that SMAD phosphorylation might be initiated with different kinetics by exogenous TGF $\beta$ than by overexpression of constitutively active receptors.

As neither caALK5 nor caALK1 overexpression induced chondrogenic differentiation in single overexpression experiments, this suggests that both receptors are required to induce chondrogenesis. When co-transducing cells with two constructs, we cannot ensure double targeting of all single cells which is crucial for drawing conclusions on the impact of dual receptor overexpression on chondrogenesis. Instead, we determined the requirement of both receptors for chondrogenic differentiation by downregulating either ALK5 or ALK1 expression with short hairpin RNA. We show that knocking down either one of the two TGF $\beta$ receptors prevented chondrogenic induction by TGF $\beta$, confirming that without the presence of both receptors chondrogenesis will not occur. Similar to our observation when we specifically downregulated ALK5, also inhibition of ALK5 with a small molecule (ALK5i) was reported to prevent chondrogenesis [38]. Although small molecule inhibitors might have off-target effects [39], the results of Elkasrawy et al. [38] and our study prove a crucial role for ALK5 in chondrogenic differentiation of BMSCs. Additionally, the importance of ALK5 in chondrogenesis is supported in vivo as mice with conditional knockout of ALK5 in skeletal progenitor cells had impaired endochondral bone formation; a process wherein mesenchymal stem cells first differentiate into chondrocytes which then terminally differentiate and eventually are replaced by bone cells [40]. Regarding the involvement of ALK1 in chondrogenesis, overexpression of kinase-inactive ALK1 receptors was previously found to block spontaneous cartilage nodule formation in a murine chondrogenic cell line [35]. We show here that shRNA-mediated downregulation of ALK1 in human BMSCs strongly reduced TGF $\beta$-induced chondrogenic differentiation, further supporting that besides ALK5 also ALK1 is required for chondrogenesis.

To the best of our knowledge, this study is first to demonstrate ALK5 and ALK1 gene expression in in vitro-expanded human BMSCs as well as in chondrogenically differentiating human BMSC pellet cultures. We show that TGF $\beta$, besides inducing chondrogenic differentiation of BMSCs, regulated expression of its receptors by enhancing ALK5 expression whilst downregulating ALK1 expression, skewing the balance between its two receptors towards ALK5. This is in line with previous reports demonstrating that TGF $\beta$ enhanced ALK5 gene expression in human smooth muscle cells, pancreatic epithelial cells and lung fibroblasts [4143]. However, also the opposite was shown as TGF $\beta$ downregulated ALK5 mRNA and protein levels in human articular chondrocytes [44], suggesting that the effects of TGF $\beta$ on ALK5 expression might be culture condition- or cell type-dependent. So far, the effect of TGF $\beta$ on ALK1 was investigated in only two studies. Whereas TGF $\beta$ did not change ALK1 expression in neurons [45], TGF $\beta$ reduced ALK1 mRNA levels in human endothelial cells, which is similar to our observation in human BMSCs [46]. Moreover, in line with the observed effect of TGF $\beta$ on ALK1 receptor expression, we also demonstrate that caALK5 overexpression reduced ALK1 mRNA levels whereas downregulation of ALK5 enhanced ALK1 gene expression. In addition 
to a change in balance between ALK5 and ALK1 receptor levels by TGF $\beta$, we show that the mRNA levels of ALK5 and ALK1 varied between different BMSC donors during onset of chondrogenesis. Previously, ALK5 gene expression was shown by us to correlate with expression of ACAN and COL2 in human OA cartilage [24]. Although the chondrogenic capacity of different BMSC donors was diverse in our study, we could not find an association between ALK5 or ALK1 gene expression levels and the chondrogenic differentiation capacity of BMSCs. Since both TGF $\beta$ receptors appeared necessary for chondrogenesis of BMSCs, the importance of balance, timing of expression and activity of ALK5 and ALK1 deserves more attention in future studies.

In our study we used human BMSCs from both adult and fetal origin. Recently, Brady et al. found that TGF $\beta 3$ could induce chondrogenesis in adult BMSC pellets, whereas TGF $\beta 3$ as well as TGF $\beta 1$ did not initiate chondrogenic differentiation of fetal BMSC pellet cultures [47]. The authors suggested that, apparently, adult and fetal BMSCs use different signaling mechanisms for inducing chondrogenic differentiation. In our experiments, however, both adult and fetal BMSC pellets did form cartilage matrix molecules following stimulation with TGF $\beta 1$ and the mRNA levels of ALK5 and ALK1 as well as their response to TGF $\beta 1$ was similar. Because our observation is not in line with the findings from Brady et al., further investigation is necessary to exactly determine the dependency of chondrogenesis on TGF $\beta$ and whether this is related to the source and developmental stage of human BMSCs.

Our study provides new insights regarding the involvement of ALK5 and ALK1 in chondrogenesis induced by TGF $\beta$. This new knowledge helps to better understand the molecular events that control chondrogenic differentiation of mesenchymal stem cells, which is important for developing procedures to optimize articular cartilage repair.

\section{Acknowledgments}

The authors would like to thank Prof. Dr. P. ten Dijke (Leiden University Medical Center, the Netherlands) for providing adenoviruses overexpressing constitutively active ALK5 or constitutively active ALK1 or LacZ, and plasmid DNA of MISSION® (Sigma-Aldrich) TRC-Hs1.5 shRNA clones targeting ALK5 (TRCN0000039773) or ALK1 (TRCN0000000355) and Empty Vector Control (SHC001). The II-II6B3 monoclonal antibody against collagen type II developed by T.F. Linsenmayer was obtained from the Developmental Studies Hybridoma Bank, originally developed under the auspices of the National Institute of Child Health and Human Development and maintained by The University of Iowa, Department of Biology (Iowa City, IA).

\section{Author Contributions}

Conceived and designed the experiments: LMGdK RN ENBD GJVMvO PMvdK. Performed the experiments: LMGdK MAC WJLMK. Analyzed the data: LMGdK RN ENBD MAC GJVMvO PMvdK. Contributed reagents/materials/analysis tools: HMvB WJLMK. Wrote the paper: LMGdK RN ENBD GJVMvO PMvdK.

\section{References}

1. Muir H. The chondrocyte, architect of cartilage. Biomechanics, structure, function and molecular biology of cartilage matrix macromolecules. BioEssays: news and reviews in molecular, cellular and developmental biology. 1995; 17(12):1039-48. doi: 10.1002/bies.950171208 PMID: 8634065.

2. Shelbourne KD, Jari S, Gray T. Outcome of untreated traumatic articular cartilage defects of the knee: a natural history study. The Journal of bone and joint surgery American volume. 2003; 85-A Suppl 2:816. PMID: 12721340. 
3. Hunziker EB, Lippuner K, Keel MJ, Shintani N. An educational review of cartilage repair: precepts \& practice - myths \& misconceptions-progress \& prospects. Osteoarthritis and cartilage / OARS, Osteoarthritis Research Society. 2015; 23(3):334-50. doi: 10.1016/j.joca.2014.12.011 PMID: 25534362.

4. Yamasaki S, Mera H, Itokazu M, Hashimoto Y, Wakitani S. Cartilage Repair With Autologous Bone Marrow Mesenchymal Stem Cell Transplantation: Review of Preclinical and Clinical Studies. Cartilage. 2014; 5(4):196-202. doi: 10.1177/1947603514534681 PMID: 26069698; PubMed Central PMCID: PMC4335770.

5. Cassiede P, Dennis JE, Ma F, Caplan AI. Osteochondrogenic potential of marrow mesenchymal progenitor cells exposed to TGF-beta 1 or PDGF-BB as assayed in vivo and in vitro. J Bone Miner Res. 1996; 11(9):1264-73. doi: 10.1002/jbmr.5650110911 PMID: 8864901.

6. Johnstone B, Hering TM, Caplan Al, Goldberg VM, Yoo JU. In vitro chondrogenesis of bone marrowderived mesenchymal progenitor cells. Experimental cell research. 1998; 238(1):265-72. doi: 10.1006/ excr.1997.3858 PMID: 9457080.

7. Mackay AM, Beck SC, Murphy JM, Barry FP, Chichester CO, Pittenger MF. Chondrogenic differentiation of cultured human mesenchymal stem cells from marrow. Tissue engineering. 1998; 4(4):415-28. PMID: 9916173.

8. Muraglia A, Cancedda R, Quarto R. Clonal mesenchymal progenitors from human bone marrow differentiate in vitro according to a hierarchical model. Journal of cell science. 2000; 113(7):1161-6. PMID: WOS:000086855400007.

9. Pittenger MF, Mackay AM, Beck SC, Jaiswal RK, Douglas R, Mosca JD, et al. Multilineage potential of adult human mesenchymal stem cells. Science. 1999; 284(5411):143-7. doi: 10.1126/science.284. 5411.143 PMID: WOS:000079509000053.

10. Wakitani S, Goto T, Pineda SJ, Young RG, Mansour JM, Caplan Al, et al. Mesenchymal cell-based repair of large, full-thickness defects of articular cartilage. The Journal of bone and joint surgery American volume. 1994; 76(4):579-92. PMID: 8150826.

11. Yoo JU, Barthel TS, Nishimura K, Solchaga L, Caplan AI, Goldberg VM, et al. The chondrogenic potential of human bone-marrow-derived mesenchymal progenitor cells. The Journal of bone and joint surgery American volume. 1998; 80(12):1745-57. PMID: 9875932.

12. De Bari C, Dell'Accio F, Luyten FP. Failure of in vitro-differentiated mesenchymal stem cells from the synovial membrane to form ectopic stable cartilage in vivo. Arthritis and rheumatism. 2004; 50(1):14250. doi: 10.1002/art.11450 PMID: 14730610.

13. Kaul G, Cucchiarini M, Remberger K, Kohn D, Madry H. Failed cartilage repair for early osteoarthritis defects: a biochemical, histological and immunohistochemical analysis of the repair tissue after treatment with marrow-stimulation techniques. Knee surgery, sports traumatology, arthroscopy: official journal of the ESSKA. 2012; 20(11):2315-24. doi: 10.1007/s00167-011-1853-x PMID: 22222614.

14. Pelttari K, Winter A, Steck E, Goetzke K, Hennig T, Ochs BG, et al. Premature induction of hypertrophy during in vitro chondrogenesis of human mesenchymal stem cells correlates with calcification and vascular invasion after ectopic transplantation in SCID mice. Arthritis and rheumatism. 2006; 54(10):325466. doi: 10.1002/art.22136 PMID: 17009260.

15. Wakitani S, Yamamoto T. Response of the donor and recipient cells in mesenchymal cell transplantation to cartilage defect. Microscopy research and technique. 2002; 58(1):14-8. doi: 10.1002/jemt. 10111 PMID: 12112417.

16. Seyedin SM, Thompson AY, Bentz H, Rosen DM, McPherson JM, Conti A, et al. Cartilage-inducing factor-A. Apparent identity to transforming growth factor-beta. The Journal of biological chemistry. 1986; 261(13):5693-5. PMID: 3754555.

17. Ebner R, Chen RH, Shum L, Lawler S, Zioncheck TF, Lee A, et al. Cloning of a type I TGF-beta receptor and its effect on TGF-beta binding to the type II receptor. Science. 1993; 260(5112):1344-8. PMID: 8388127.

18. Attisano L, Carcamo J, Ventura F, Weis FM, Massague J, Wrana JL. Identification of human activin and TGF beta type I receptors that form heteromeric kinase complexes with type II receptors. Cell. 1993; 75 (4):671-80. PMID: 8242742.

19. Franzen $\mathrm{P}$, ten Dijke $\mathrm{P}$, Ichijo $\mathrm{H}$, Yamashita $\mathrm{H}$, Schulz $\mathrm{P}$, Heldin $\mathrm{CH}$, et al. Cloning of a TGF beta type I receptor that forms a heteromeric complex with the TGF beta type II receptor. Cell. 1993; 75(4):681-92. PMID: 8242743.

20. Yamashita H, ten Dijke P, Franzen $\mathrm{P}$, Miyazono K, Heldin $\mathrm{CH}$. Formation of hetero-oligomeric complexes of type I and type II receptors for transforming growth factor-beta. The Journal of biological chemistry. 1994; 269(31):20172-8. Epub 1994/08/05. PMID: 8051105.

21. Heldin $\mathrm{CH}$, Miyazono $\mathrm{K}$, tenDijke P. TGF-beta signalling from cell membrane to nucleus through SMAD proteins. Nature. 1997; 390(6659):465-71. PMID: ISI:A1997YJ86500039. 
22. Nakao A, Imamura T, Souchelnytskyi S, Kawabata M, Ishisaki A, Oeda E, et al. TGF-beta receptormediated signalling through Smad2, Smad3 and Smad4. The EMBO journal. 1997; 16(17):5353-62. Epub 1997/10/06. doi: 10.1093/emboj/16.17.5353 PMID: 9311995; PubMed Central PMCID: PMC1170167.

23. ten Dijke $P$, Hill CS. New insights into TGF-beta-Smad signalling. Trends in biochemical sciences. 2004; 29(5):265-73. Epub 2004/05/08. doi: 10.1016/j.tibs.2004.03.008 PMID: 15130563.

24. Blaney Davidson EN, Remst DF, Vitters EL, van Beuningen HM, Blom AB, Goumans MJ, et al. Increase in ALK1/ALK5 ratio as a cause for elevated MMP-13 expression in osteoarthritis in humans and mice. J Immunol. 2009; 182(12):7937-45. doi: 10.4049/jimmunol.0803991 PMID: 19494318.

25. Finnson KW, Parker WL, ten Dijke P, Thorikay M, Philip A. ALK1 opposes ALK5/Smad3 signaling and expression of extracellular matrix components in human chondrocytes. J Bone Miner Res. 2008; 23 (6):896-906. Epub 2008/03/13. doi: 10.1359/jbmr.080209 PMID: 18333754.

26. Goumans MJ, Lebrin F, Valdimarsdottir G. Controlling the angiogenic switch: a balance between two distinct TGF-b receptor signaling pathways. Trends in cardiovascular medicine. 2003; 13(7):301-7. PMID: 14522471.

27. Goumans MJ, Mummery C. Functional analysis of the TGFbeta receptor/Smad pathway through gene ablation in mice. The International journal of developmental biology. 2000; 44(3):253-65. Epub 2000/ 06/15. PMID: 10853822.

28. Goumans MJ, Valdimarsdottir G, Itoh S, Lebrin F, Larsson J, Mummery C, et al. Activin receptor-like kinase (ALK) 1 is an antagonistic mediator of lateral TGFbeta/ALK5 signaling. Molecular cell. 2003; 12 (4):817-28. PMID: 14580334.

29. Goumans MJ, Valdimarsdottir G, Itoh $S$, Rosendahl A, Sideras P, ten Dijke P. Balancing the activation state of the endothelium via two distinct TGF-beta type I receptors. EMBO Journal. 2002; 21(7):174353. PMID: 11927558.

30. Oh SP, Seki T, Goss KA, Imamura T, Yi Y, Donahoe PK, et al. Activin receptor-like kinase 1 modulates transforming growth factor-beta 1 signaling in the regulation of angiogenesis. Proc Natl Acad Sci U S A. 2000; 97(6):2626-31. Epub 2000/03/16. PMID: 10716993; PubMed Central PMCID: PMC15979.

31. Chen YG, Massague J. Smad1 recognition and activation by the ALK1 group of transforming growth factor-beta family receptors. Journal of Biological Chemistry. 1999; 274(6):3672-7. PMID: 9920917.

32. Hellingman CA, Davidson EN, Koevoet W, Vitters EL, van den Berg WB, van Osch GJ, et al. Smad signaling determines chondrogenic differentiation of bone-marrow-derived mesenchymal stem cells: inhibition of Smad1/5/8P prevents terminal differentiation and calcification. Tissue engineering Part $A$. 2011; 17(7-8):1157-67. Epub 2010/12/15. doi: 10.1089/ten.TEA.2010.0043 PMID: 21142619.

33. Itoh S, Thorikay M, Kowanetz M, Moustakas A, Itoh F, Heldin CH, et al. Elucidation of Smad requirement in transforming growth factor-beta type I receptor-induced responses. The Journal of biological chemistry. 2003; 278(6):3751-61. doi: 10.1074/jbc.M208258200 PMID: 12446693.

34. Van Obberghen-Schilling E, Roche NS, Flanders KC, Sporn MB, Roberts AB. Transforming growth factor beta 1 positively regulates its own expression in normal and transformed cells. The Journal of biological chemistry. 1988; 263(16):7741-6. Epub 1988/06/05. PMID: 3259578.

35. Fuji M, Takeda K, Imamura T, Aoki H, Sampath TK, Enomoto S, et al. Roles of bone morphogenetic protein type I receptors and smad proteins in osteoblast and chondroblast differentiation. Molecular biology of the cell. 1999; 10(11):3801-13. PMID: WOS:000083647300021.

36. Melke $\mathrm{P}$, Jonsson $\mathrm{H}$, Pardali E, ten Dijke $\mathrm{P}$, Peterson $\mathrm{C}$. A rate equation approach to elucidate the kinetics and robustness of the TGF-beta pathway. Biophysical journal. 2006; 91(12):4368-80. doi: 10.1529/ biophysj.105.080408 PMID: 17012329; PubMed Central PMCID: PMC1779910.

37. Zi Z, Chapnick DA, Liu X. Dynamics of TGF-beta/Smad signaling. FEBS letters. 2012; 586(14):1921-8. doi: 10.1016/j.febslet.2012.03.063 PMID: 22710166; PubMed Central PMCID: PMC4127320.

38. Elkasrawy M, Fulzele S, Bowser M, Wenger K, Hamrick M. Myostatin (GDF-8) inhibits chondrogenesis and chondrocyte proliferation in vitro by suppressing Sox-9 expression. Growth factors. 2011; 29 (6):253-62. doi: 10.3109/08977194.2011.599324 PMID: 21756198; PubMed Central PMCID: PMC3738019.

39. Vogt J, Traynor R, Sapkota GP. The specificities of small molecule inhibitors of the TGFss and BMP pathways. Cellular signalling. 2011; 23(11):1831-42. doi: 10.1016/j.cellsig.2011.06.019 PMID: 21740966.

40. Matsunobu T, Torigoe K, Ishikawa M, de Vega S, Kulkarni AB, Iwamoto Y, et al. Critical roles of the TGF-beta type I receptor ALK5 in perichondrial formation and function, cartilage integrity, and osteoblast differentiation during growth plate development. Developmental biology. 2009; 332(2):325-38. doi: 10.1016/j.ydbio.2009.06.002 PMID: 19501582; PubMed Central PMCID: PMC2716725. 
41. Bloom BB, Humphries DE, Kuang PP, Fine A, Goldstein RH. Structure and expression of the promoter for the R4/ALK5 human type I transforming growth factor-beta receptor: regulation by TGF-beta. Biochimica et biophysica acta. 1996; 1312(3):243-8. PMID: 8703994.

42. Menke A, Geerling I, Giehl K, Vogelmann R, Reinshagen M, Adler G. Transforming growth factor-betainduced upregulation of transforming growth factor-beta receptor expression in pancreatic regeneration. Biochimica et biophysica acta. 1999; 1449(2):178-85. PMID: 10082976.

43. Moreland RB, Traish A, McMillin MA, Smith B, Goldstein I, Saenz de Tejada I. PGE1 suppresses the induction of collagen synthesis by transforming growth factor-beta 1 in human corpus cavernosum smooth muscle. The Journal of urology. 1995; 153(3 Pt 1):826-34. PMID: 7861547.

44. Bauge $\mathrm{C}$, Cauvard O, Leclercq S, Galera $\mathrm{P}$, Boumediene $\mathrm{K}$. Modulation of transforming growth factor beta signalling pathway genes by transforming growth factor beta in human osteoarthritic chondrocytes: involvement of Sp1 in both early and late response cells to transforming growth factor beta. Arthritis research \& therapy. 2011; 13(1):R23. PMID: 21324108.

45. Konig HG, Kogel D, Rami A, Prehn JH. TGF-\{beta\}1 activates two distinct type I receptors in neurons: implications for neuronal NF-\{kappa\}B signaling. The Journal of cell biology. 2005; 168(7):1077-86. doi: 10.1083/jcb.200407027 PMID: 15781474; PubMed Central PMCID: PMC2171851.

46. Lux A, Salway F, Dressman HK, Kroner-Lux G, Hafner M, Day PJ, et al. ALK1 signalling analysis identifies angiogenesis related genes and reveals disparity between TGF-beta and constitutively active receptor induced gene expression. BMC Cardiovasc Disord. 2006; 6:13. PMID: 16594992.

47. Brady K, Dickinson SC, Guillot PV, Polak J, Blom AW, Kafienah W, et al. Human fetal and adult bone marrow-derived mesenchymal stem cells use different signaling pathways for the initiation of chondrogenesis. Stem cells and development. 2014; 23(5):541-54. Epub 2013/11/01. doi: 10.1089/scd.2013. 0301 PMID: 24172175; PubMed Central PMCID: PMC3929258. 